of thymine dimers in ultraviolet irradiated DNA, and inhibition of bacterial transformation.

A whole section is devoted to the adjuvant effect of nucleic acids. Antibody-forming cells may be stimulated by oligonucleotides of known composition. Another section is concorned with the role of nucleic acids in specific antibody formation. Obviously, nucleic acids play a central part in the synthesis of antibodies, similar to their role in the biosynthesis of other proteins. As to the origin and the possible "informational" role of the nucleic acid, most problems are still open and under very active investigation. The first reports on in vitro investigations of immunoglobulin biosynthesis are also included in this book, which ends with the text of a speech on "The Molecular Biology of Expectation" presented at the symposium banquet by $\mathrm{Dr}$ Melvin Cohn. $\mathrm{He}$ discusses the mechanism by which an individual can react in an adaptive way to an unexpected stimulus. The three systems responding to unexpected stimuli are the immune, detoxifying and learning mechanisms.

Undoubtedly, this is a very interesting book, containing a lot of new experimental results as well as food for thought for everybody interested in nucleic acids, in immunoglobulins and-more generally-in immunology, biochemistry and geneties.

Michaet Sela

\section{FUNDAMENTAL PROCESSES}

\section{Protons, Electrons, Phosphorylation and Active} Transport

By R. N. Robertson. (Cambridge Monographs in Experimental Biology, No. 15.) Pp. vii +96 . (Cambridge University Press: London, October 1968.) 32s; $\$ 5.50$.

THE title of this book and the current interest in its subject might have led one to expect a work of fairly massive proportions. It is an indication of Professor Robertson's skill that he has in fact written a book of only eighty-four pages. In these eighty-four pages we are given not just a botanist's viewpoint, valuable though this is, but an extended and wide ranging essay in which many seemingly divergent processes connected with active transport and phosphorylation in plants and animals are seen in perspective and integrated with one another.

In his introduction, Robertson makes it clear that he considers the production of protons and electrons from the hydrogen atoms of water or organic molecules to be a very fundamental biological process and this concept underlies the whole book. The first chapter deals with certain theories of active transport originating with Lundegårdh's hypothesis, while the second chapter leads to the extension of these ideas into Mitchell's hypothesis. When the history of the investigation of oxidative phosphorylation comes to be written, Mitchell's hypothesis will be seen to have played a vitally important part even if it eventually turns out to be incorrect. This hypothesis has forced biochemists to think about oxidative phosphorylation in an entircly new way and has stimulated a great deal of important experimental work, in particular on ion movements in mitochondria. It is evident that Robertson admires the hypothesis and he seems more ready to accept the idea of a potential of $210 \mathrm{mV}$ across the mitochondrial membrane than perhaps an electrophysiologist or biophysicist would. In later chapters, Robertson discusses the extension of the idea of protonelectron separation and Mitchell's hypothesis into photosynthesis and active transport, special mention being made under the latter heading of the gastric mucosa, anion pumps in plant cells and cation pumps.

This book can be unreservedly recommended to anybody wishing to obtain an insight into the present state of work and ideas in this fascinating field.

Peter C. Caldwell

\section{SYNTHESES OPPOSED}

\section{Antagonists and Nucleic Acids}

By M. Earl Balis. (North-Holland Research Monographs: Frontiers of Biology, Vol. 10.) Pp. $\mathrm{x}+293$. (North-Holland: Amsterdam, 1968.) 126.s.

THE development of metabolic antagonists and the study of their mechanism of action have adranced rapidly in recent years. Compounds affecting nucleic acid biosynthesis and function are of particular interest because of their value in fundamental studies in molecular biology, virology and microbiology and also in the more practical fields of immunosuppression and cancer chemotherapy. This monograph is therefore timely.

The book opens with an introduction followed by chapters reviewing relevant knowledge on purine and pyrimidine biosynthesis and interconversion, transcription of genetic information and replication of the genetic material with descriptions of various inhibitors which are known or thought to act by interference with these processes. Later chapters deal with incorporation of analogues into nucleic acids, the action of alkylating agents and with inhibitors of protein synthesis. The final chapter, written by Dr George B. Brown, deals with purine $\mathrm{N}$-oxides as antimetabolites and carcinogens.

The principal group of antagonists of transcription and replication are thought to bind to nucleic acids and include a number of antibiotics and synthetic polycyclic molecules. A clear account is given of actinomycin D and its postulated binding in the minor groove of helical DNA which is contrasted with the intercalation mechanism proposed for the acridines. The interesting double role of ethidium bromide as a chemotherapeutic agent against trypanosomes and as a valuable adjunct to caesium gradient centrifugation studies of DNA is brought out and illustrates the interplay between fundamental and applied research. The explosive growth of research on aflatoxin makes it impossible to cover in any detail in the space available. Nevertheless, an sdequate account of this remarkable toxin and carcinogen is given. 'The incorporation of analogues is, again, an enormous field of which the author has given a woll balanced account. He emphasizes the remarkable extent to which incorporation may occur, with, for example, 8-azaguanine, which "the orthodox believer in molecular specificity" finds hard to reconcile with its lack of effect on some biochemical reactions of the nucleic acid.

The capacity of the alkylating agents for mutagenesis, carcinogenesis and cytotoxicity has led to extensive investigations and a selective account of this work is provided. Work on alkylation of nucleic acids in vivo and in vitro is reviewed with discussion of cross-linking and repair of DNA and the possible significance of alkylation of RNA and protein. The author concludes that the mechanism of action of the alkylating agents is still unsettled and emphasizes that the final explanation must, be applicable to mammalian cells as well as to bacteria. Many inhibitors of protein synthesis are thought to act by interference with nucleic acids. The mechanisms of action of puromycin, streptomycin and chloramphenicol are discussed critically. The action of chloramphenicol on protein synthesis in mammalian systems could, perhaps, have received rather more detailed treatment. The purine $\mathrm{N}$-oxides were first investigated for antimetabolite activity during the past decade. Although many of thom failed to show significant anti-cancer action, some can induce tumours. Possible similarities betwcen the action of the purine $\mathrm{N}$-oxides and the $\mathrm{N}$-hydroxy derivatives of aromatic amines are discussed with the conclusion that there is no reason to associate tho two groups with one another or to classify the purine $\mathbf{N}$-oxide as with 4 -nitroquinoline $\mathrm{N}$-oxide. The author claims that, with certain possible exceptions, the purine $\mathrm{N}$-oxides are the only chemical carcinogens derived from compounds common to all cells. He admits that there is no evidence that they 